\title{
Prompt gamma rays induced by inelastic scattering of fission neutrons on iron
}

\author{
Zeljko Ilic $^{1,2} \cdot$ Eric Mauerhofer $^{1} \cdot$ Christian Stieghorst $^{3} \cdot$ Zsolt Révay $^{3} \cdot$ Matthias Rossbach $^{4}$. \\ Tsitohaina H. Randriamalala' ${ }^{1}$. Thomas Brückel ${ }^{1,2}$
}

Received: 24 April 2020 / Published online: 6 July 2020

(C) The Author(s) 2020

\begin{abstract}
Prompt gamma rays induced by $\left(n, n^{\prime} \gamma\right)$ reactions on iron were measured with the instrument FanGaS (Fast Neutron induced Gamma-Ray Spectrometry) operated at the Heinz Maier-Leibnitz Zentrum (MLZ) in Garching. The measurement was performed at an angle of $90^{\circ}$ between neutron beam and detector. The fast neutron flux at the sample position was determined to be $1.40 \times 10^{8} \mathrm{~cm}^{-2} \mathrm{~s}^{-1}$ by using the foil activation method. Energies, relative intensities and fast neutron spectrum averaged isotopic cross section for production of 81 prompt gamma lines are presented. The results obtained are found in good agreement with literature data. The new set of gamma lines is recommended to replace the old dataset with several new lines also recognizing a few false identifications. This work is an important step towards the future chemical analysis of large samples at FanGaS employing highly penetrating fission neutrons.
\end{abstract}

Keywords Fast neutrons · Iron · Inelastic scattering · Prompt gamma ray $\cdot$ Cross section

\section{Introduction}

Accurate non-destructive chemical analysis of materials is of fundamental importance in many fields of science and for industrial applications. Prompt Gamma Neutron Activation Analysis (PGNAA) based on cold/thermal neutron capture is well established as a powerful non-destructive analytical technique to determine the elemental composition of small and thin samples [1]. Large objects may be investigated to some extent by PGNAA using cold or thermal neutron beams [2-4]. Nevertheless, depending on the neutron absorption properties of the sample, the penetration depth of cold/thermal neutrons is limited and the beam attenuation must be corrected for $[4,5]$. Therefore, neutrons of higher

Eric Mauerhofer

e.mauerhofer@fz-juelich.de

1 Jülich Centre for Neutron Science, Forschungszentrum Jülich GmbH, 52425 Jülich, Germany

2 Lehrstuhl für Experimentalphysik IVc, RWTH Aachen University, 52056 Aachen, Germany

3 Heinz Maier-Leibnitz Zentrum (MLZ), Technische Universität München, Lichtenbergstr, 85748 Garching, Germany

4 Kreuzau, Germany energies are a better choice for the analysis of large and thick objects. Unlike cold/thermal neutrons inducing (n, $\gamma$ ) reactions, high-energy neutrons induce other reactions, particularly $\left(n, n^{\prime}\right)$ or $(n, p),(n, \alpha)$ or even $(n, 2 n)$ in some cases. Cross sections for these reactions are generally lower compared to thermal neutron capture reactions. However, as capture cross sections outside nuclear resonances follow a $1 / v$ trend $(v$ being the neutron velocity), at higher energies e.g. at $2 \mathrm{MeV}$ mean energy of fission neutrons, inelastic scattering with the emission of isotope-specific prompt gamma rays prevail.

The possibility to determine the elemental composition of large samples by measuring prompt gamma rays with a $\mathrm{NaI}(\mathrm{Tl})$ detector following the inelastic scattering of $14-\mathrm{MeV}$ pulsed neutrons for remote analysis of surfaces was reported first in 1961 by Schrader and Stinner [6]. In 1976, Jiggins and Habbani [7] used 3.29 MeV neutrons, produced by the ${ }^{2} \mathrm{H}(\mathrm{d}, \mathrm{n}){ }^{3} \mathrm{He}$ reaction, for the determination of iron in iron ores measuring prompt gamma rays with a $\mathrm{NaI}(\mathrm{Tl})$ detector and presented analytical sensitivities for 23 elements. Two years later, Yates et al. [8] proposed a time-of-flight method based on neutron/gamma coincidence to improve sensitivity of prompt gamma-ray detection with a $\mathrm{Ge}(\mathrm{Li})$ detector rejecting background signals induced by scattered neutrons. The method was applied to the analysis of metal alloys using $2.5 \mathrm{MeV}$ neutrons and limits of detection for 38 elements 
were determined. In 1979, Sowerby [9] investigated the use of isotopic neutron sources for elemental analysis of kilogram samples by neutron inelastic scattering associated gamma rays. These preliminary works have resulted in the following years till now to the development of various laboratories, in situ or online techniques using either isotopic neutron sources or neutron generators and mainly scintillation detectors ( $\mathrm{NaI}(\mathrm{Tl}), \mathrm{BGO}$ or $\mathrm{LaBr}_{3}$ ) for bulk analysis (well and bore-hole logging, process and quality control of materials such as coal, cement and ores) or for detection of explosive and illicit materials. However, due to the low fast neutron flux delivered by these sources and the poor resolution of the employed detectors, the analytical sensitivity of the developed techniques is limited to few \% per sample weight. Therefore, it was decided to use the intense fission neutron beam delivered by the SR10 (Strahlrohr 10) channel of the research reactor FRM II (Forschungs-Neutronenquelle Heinz-Maier-Leibnitz) for accurate analysis of large samples measuring prompt gamma rays induced by inelastic scattering of fission neutrons.

Compared to the well documented thermal neutron prompt gamma spectra and associated energies [1], a tabulation of prompt gamma energies and associated relative intensities induced by fission neutrons of all elements has been published only once in 1978 by Demidov et al. [10]. The measurements were performed at the Baghdad Nuclear Research Institute, while the evaluation has been carried out at the Kurchatov Institute, Moscow. A fission neutron beam (filtered with $9 \mathrm{~cm}$ of lead, $1 \mathrm{~cm}$ boron carbide and $1 \mathrm{~mm}$ of cadmium) with the diameter of $3 \mathrm{~cm}$ was used for the irradiation. The gamma rays emitted by the sample under 90 degrees were filtered using $8 \mathrm{~cm}$ of $\mathrm{LiH}$ and acquired by a $30-\mathrm{cm}^{3}$ (equivalent to $10 \%$ relative efficiency) $\mathrm{Ge}(\mathrm{Li}$ ) detector. The detector was shielded with $5 \mathrm{~cm}$ iron, $8 \mathrm{~cm}$ boron carbide-loaded paraffin, $10 \mathrm{~cm}$ of lead, and $3 \mathrm{~mm}$ of ${ }^{6} \mathrm{Li}$. This pioneering work covering a reasonable range of gamma-ray energies is valuable. However, the energy resolution of the $\mathrm{Ge}(\mathrm{Li})$ detector was degrading after an extended neutron exposure. Thus, to perform precise chemical analysis of samples with fission neutrons a comprehensive data catalogue on $\left(n, n^{\prime} \gamma\right)$ reactions, prompt gamma-ray energies and absolute intensities is urgently needed. Furthermore, these data may help in the development of nuclear data libraries that serve a multitude of applications.

To achieve this, the FaNGaS (Fast Neutron induced Gamma Spectrometry) instrument $[11,12]$ has been designed and installed at the MEDAPP (Medical Application) [13] facility of FRM II (Fig. 1). The first characterization of FaNGaS and the neutron spectrum at sample position is given in [11]. In this work, the fast neutron spectrum and flux at sample position is determined again due to a modification of the fast neutron collimation. The results obtained from the measurement of prompt gamma rays induced by

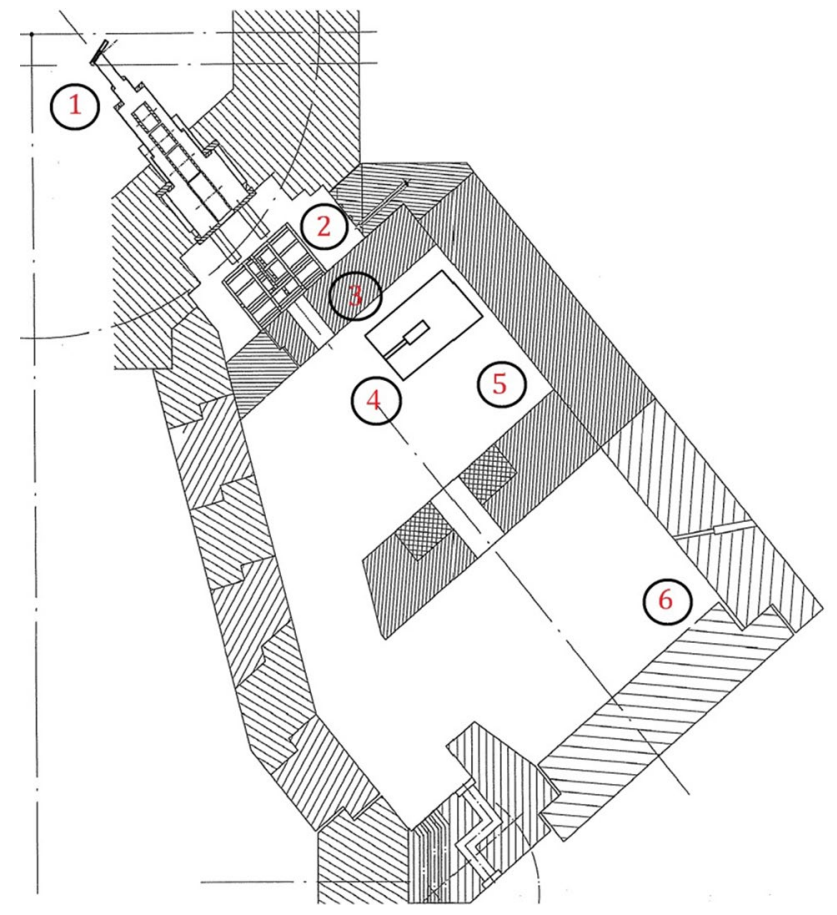

Fig. 1 Schematic view of the fast neutron facility at FRM II. (1) convertor plate made of $498 \mathrm{~g}$ of highly enriched uranium (93\% of ${ }^{235} \mathrm{U}$ ) plunged into the reactor pool at at disatnce of about $1 \mathrm{~m}$ for the reactor core; (2) bench filters bunker containing the collimator of FaNGaS instrument; (3) mutli-leaf-collimator of the MEDAPP facility; (4) FaNGaS spectrometer at measuring position; (5) bunker of the MEDAPP facility; (6) bunker of the NECTAR facility

inelastic scattering of fission neutrons on iron at an angle of $90^{\circ}$ between the neutron beam and the detector are presented and compared to literature data.

\section{FaNGaS instrument}

In the first version of the FaNGaS instrument the collimation of fast neutrons was achieved using a set of two collimators made of polyethylene, boron carbide and lead. The inner collimator was placed inside the filter bench room while the outer collimator was positioned in the opening of the multileaf-collimator of the irradiation facility MEDAPP inside the biological shield. Technical details and dimensions of the collimators are given in [11]. Due to the upgrade of the fast neutron imaging facility NECTAR (Neutron Computerized Tomography and Radiography) to perform radiography or tomography also with thermal neutrons [14], the filter setups inside the filter bench room have been modified and the FaNGaS outer collimator was removed from the MEDAPP multi-leaf-collimator. In order to filter thermal neutrons from the fast neutron beam and to attenuate gamma radiation coming from the reactor, a boron carbide plate with a thickness of $1 \mathrm{~cm}$ and two lead plates with a total thickness of $5 \mathrm{~cm}$ 
were placed at the upstream beam side of the inner collimator (see Fig. 2). Due to these changes, a new determination of the fast neutron flux at sample position was necessary.

In addition, the shielding of the HPGe-detector was also partially modified. In order to increase thermal neutron absorption, the $30 \mathrm{~cm}$ thick polyethylene layers at the front side of the shielding have been replaced by borated polyethylene of same thickness. For gamma-ray collimation, a removable cylindrical lead collimator with $6 \mathrm{~cm}$ inner diameter, $2 \mathrm{~cm}$ wall thickness and $16 \mathrm{~cm}$ length was inserted into the cylindrical aperture $(10 \mathrm{~cm}$ diameter $)$ of the front shielding. The detector set up at experimental position is shown in Fig. 2.

\section{Neutron flux determination}

The fast neutron spectrum in the energy range $0.075-20 \mathrm{MeV}$ at the sample position was determined by means of the foil activation technique. High-purity foils of various elements ( $\mathrm{Al}, \mathrm{Ti}, \mathrm{Fe}, \mathrm{Ni}, \mathrm{Zr}$ and $\mathrm{In}$ ) were sealed in Teflon bags and irradiated separately for $8-18 \mathrm{~h}$. The dimension of the foils is about $25 \times 25 \times 0.25 \mathrm{~mm}^{3}$. After irradiation, the gamma-ray spectra of the activated foils were measured at a distance of $17 \mathrm{~cm}$ from the HPGe-detector. The counting times ranged from 2 to $21 \mathrm{~h}$. The gamma-ray spectra were analyzed with the HYPERMET-PC software [15]. The reaction rates, $R$, for neutron spectrum unfolding were calculated using the following relation:

$$
R=\frac{\ln 2 \cdot P_{E \gamma}}{\varepsilon_{E \gamma} \cdot I_{E \gamma} \cdot T} \cdot \frac{e^{\frac{\ln 2 \cdot t_{\mathrm{d}}}{T}}}{\left(1-e^{\frac{-\ln 2 t_{\mathrm{i}}}{T}}\right) \cdot\left(1-e^{\frac{-\ln 2 \cdot t_{\mathrm{c}}}{T}}\right)}
$$

where $P_{E \gamma}$ is the net count for the gamma-ray of energy $E \gamma$, $\varepsilon_{E \gamma}$ is the full-energy-peak efficiency at measuring position determined in [11], $I_{E \gamma}$ the gamma emission probability, $T$ is the half-life of the activation product, $t_{\mathrm{i}}$ is the irradiation time, $t_{\mathrm{c}}$ is the counting time and $t_{\mathrm{d}}$ the decay time, i.e. the time between end of irradiation and beginning of the counting. Corrections for neutron and gamma absorption were neglected since the foils are very thin. The masses of the foils, the investigated reactions and the calculated reactions rates per atom are given in Table 1.

The software suit STASYL PNNL was used for neutron spectrum unfolding [16]. This code provides a solution for the neutron spectrum using the generalized least-square method. Detailed information about the method can be found in [17]. The code takes as input the reaction rates and a predefined neutron spectrum divided into a certain number of energy groups. For the purpose of this work, the neutron spectrum previously determined with the initial setup of neutron collimators was used as an input and the number of energy groups was set to 100 . The obtained neutron spectrum is compared with the previous one determined with the former set of neutron collimators in Fig. 3. A relatively higher average neutron energy of $2.30 \mathrm{MeV}$ and a fast neutron flux $(1.40 \pm 0.05) \times 10^{8} \mathrm{~cm}^{-2} \mathrm{~s}^{-1}$ were obtained due to the removal of the outer collimator from the MEDAPP
Fig. 2 The left piture shows detector setup at experimental position: (1) the front side of the MEDAPP multi-leaf neutron beam collimator; (2) front shielding made of borated polyethylene; (3) detector collimator; (4) sample holder made of Teflon; (5) iron support frame. The upper right picture shows the inner neutron collimator on the filter bench. The down right picture shows the boron carbide and lead filters in front of the neutron collimator
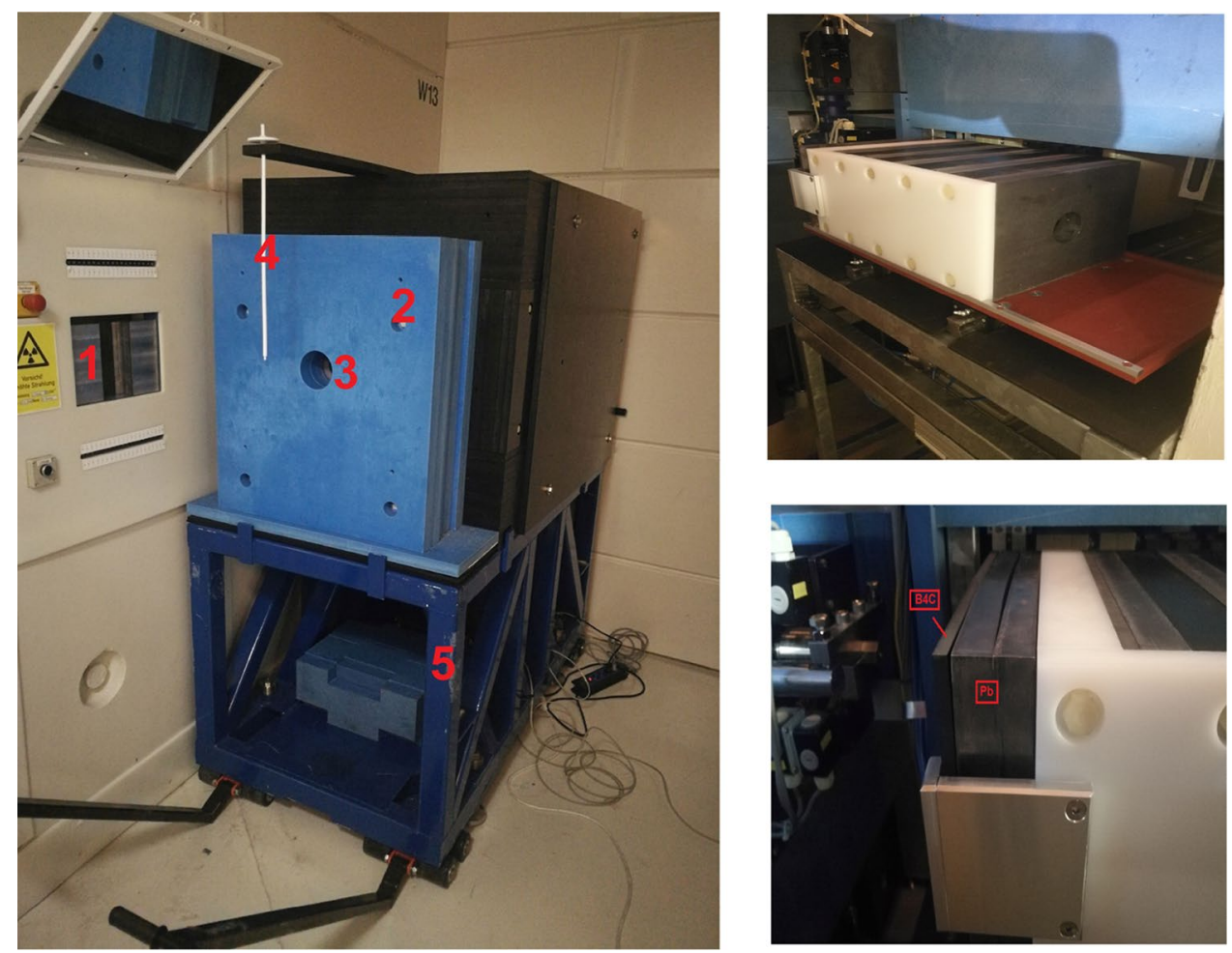
Table 1 List of irradiated foils with their respective masses, investigated reactions with their corresponding threshold energies, $E_{\text {thr }}[11]$, considered gamma-rays energy, $E \gamma$, and determined reaction rates, $R$

\begin{tabular}{llllllll}
\hline Element & Mass $(\mathrm{g})$ & Reaction & $E_{\text {thr }}(\mathrm{MeV})$ & $E \gamma(\mathrm{keV})$ & $\mathrm{R}\left(\right.$ atom $\left.^{-1} \mathrm{~s}^{-1}\right)$ & $\sigma(\mathrm{mb})$ & $\sigma_{\text {fission }}(\mathrm{mb})$ \\
\hline $\mathrm{Al}$ & 0.343 & ${ }^{27} \mathrm{Al}(\mathrm{n}, \mathrm{p})^{27} \mathrm{Mg}$ & 1.896 & 843 & $(6.22 \pm 0.14) \times 10^{-19}$ & $4.44 \pm 0.18$ & $4.32 \pm 0.16$ \\
& & ${ }^{27} \mathrm{Al}(\mathrm{n}, \alpha)^{24} \mathrm{Na}$ & 3.249 & 1368 & $(1.46 \pm 0.04) \times 10^{-19}$ & $1.04 \pm 0.05$ & $0.88 \pm 0.02$ \\
$\mathrm{Ti}$ & 0.772 & ${ }^{47} \mathrm{Ti}(\mathrm{n}, \mathrm{p})^{47} \mathrm{Sc}$ & 0.075 & 159 & $(2.83 \pm 0.07) \times 10^{-18}$ & $20 \pm 1$ & $18.3 \pm 0.6$ \\
& & ${ }^{48} \mathrm{Ti}(\mathrm{n}, \mathrm{p})^{48} \mathrm{Sc}$ & 3.276 & 1037 & $(6.40 \pm 0.35) \times 10^{-20}$ & $0.46 \pm 0.03$ & $0.37 \pm 0.03$ \\
$\mathrm{Fe}$ & 1.282 & ${ }^{56} \mathrm{Fe}(\mathrm{n}, \mathrm{p})^{56} \mathrm{Mn}$ & 2.965 & 846 & $(1.94 \pm 0.02) \times 10^{-19}$ & $1.39 \pm 0.05$ & $1.27 \pm 0.02$ \\
$\mathrm{Ni}$ & 2.806 & ${ }^{58} \mathrm{Ni}(\mathrm{n}, \mathrm{p})^{58} \mathrm{Co}$ & 0.49 & 811 & $(1.88 \pm 0.03) \times 10^{-17}$ & $134 \pm 5$ & $108 \pm 1$ \\
$\mathrm{Zr}$ & 1.109 & ${ }^{90} \mathrm{Zr}(\mathrm{n}, 2 \mathrm{n})^{89} \mathrm{Zr}$ & 12.1 & 909 & $(1.93 \pm 0.66) \times 10^{-20}$ & $0.138 \pm 0.05$ & $0.170 \pm 0.05$ \\
$\mathrm{In}$ & 1.334 & ${ }^{115} \mathrm{In}\left(\mathrm{n}, \mathrm{n}^{\prime}\right)^{115 \mathrm{~m}} \mathrm{In}$ & 0.339 & 336 & $(2.89 \pm 0.03) \times 10^{-17}$ & $206 \pm 7$ & $188 \pm 11^{\mathrm{a}}$ \\
$\mathrm{In}$ & 1.334 & ${ }^{115} \mathrm{In}(\mathrm{n}, \gamma)^{116 \mathrm{~m}} \mathrm{In}$ & - & 1097,1293 & $(5.63 \pm 0.08) \times 10^{-17}$ & - & - \\
\hline
\end{tabular}

$\sigma$ is the neutron spectrum averaged cross section of the reaction. $\sigma_{\text {fission }}$ is the cross section evaluated for a fission spectrum $(k T=1.35 \mathrm{MeV})$ in JANIS (mean value from various nuclear data libraries) [18]

${ }^{\text {a}}$ Value taken in Ref. [25]

Fig. 3 Energy spectra of the incident neutron beam of $\mathrm{FaN}$ $\mathrm{GaS}$ at sample position. Orange histogram (a): determined in the energy range $10^{-8}$ to $20 \mathrm{MeV}$ using the inner and outer neutron collimators [11]. Green histogram (b): determined in the energy range $0.075-20 \mathrm{MeV}$ using the inner neutron collimator with $\mathrm{B}_{4} \mathrm{C}$ and $\mathrm{Pb}$ filters (this work). The zoom in the figure shows the energy spectra for the fast neutron region

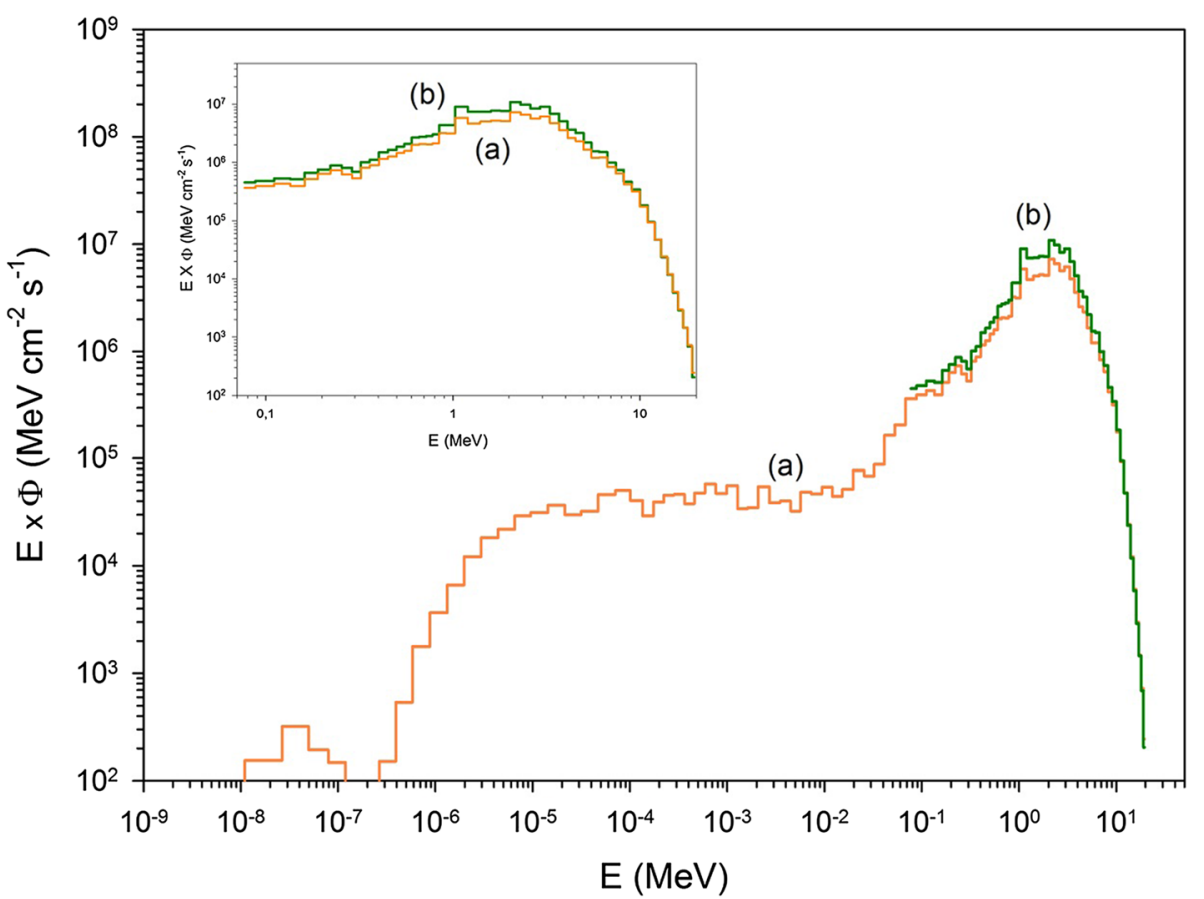

multi-leaf-collimator. The fast neutron spectrum averaged cross sections were determined according to $\sigma=R / \Phi$, for the threshold reactions listed in Table 1 . The results compare well with the values evaluated for a fission spectrum $(\mathrm{kT}=1.35 \mathrm{MeV}$ ) given in JANIS (Java-based Nuclear Data Information System) Book of neutron induced cross section [18] (see Table 1). The differences may be related to the deviation of the fast neutron spectrum from a Watt spectrum.

The neutron flux in the energy range $10^{-8}-0.075 \mathrm{MeV}$ was not determined in this work since these neutron energies are not expected to contribute significantly to the inelastic channel. As shown in Fig. 3 (orange histogram, (a)), the neutron flux integrated over this region (mainly resonance neutrons) represents only $2 \%$ of the total neutron flux. Here, we may suppose that the resonance neutron flux is almost the same since the rate measured for the reaction ${ }^{115} \operatorname{In}(\mathrm{n}, \gamma)^{116 \mathrm{~m}} \mathrm{In},(5.63 \pm 0.08) \times 10^{-17}$ atom $^{-1} \mathrm{~s}^{-1}$ is close to the value measured in [11], $(5.03 \pm 0.08) \times 10^{-17}$ atom $^{-1} \mathrm{~s}^{-1}$. (Color figure online)

\section{Prompt gamma rays of iron}

The gamma-ray spectrum of the iron foil $(m=1.282 \mathrm{~g})$ was recorded during irradiation. The measurement was performed at an angle of $90^{\circ}$ with respect to the neutron beam 
direction. The gamma lead-collimator was used. The distance between foil and detector was $67 \mathrm{~cm}$. The iron foil of natural composition was irradiated and counted for $10 \mathrm{~h}$ (live time was $7.6 \mathrm{~h}$ ). To support the identification of the prompt gamma lines, a beam background (i.e. irradiation without sample) was also recorded for $12.9 \mathrm{~h}$. The spectra were analyzed with the software HYPERMET-PC [15]. The gamma-ray spectra are shown together for various energy ranges in Figs. 4, 5, and 6. The identified isotopes with the associated gamma-ray energies are given in the spectra; those with asterisks belong to the beam background. The latter contains prompt and delayed gamma rays induced by fast neutron interaction or neutron capture with the HPGe detector $(\mathrm{Ge}, \mathrm{Al}, \mathrm{Cu}, \mathrm{In})$, the shielding $(\mathrm{B}, \mathrm{H}, \mathrm{Pb})$, the supporting frame ( $\mathrm{Fe})$, the sample holder made of Teflon $(\mathrm{F})$ and the air $(\mathrm{N}, \mathrm{O})$. It was also seen that when the lead collimator was close to the detector, the boron peak at $478 \mathrm{keV}$ is fully suppressed (Fig. 4) and the count rate of the $2223 \mathrm{keV}$
Fig. 4 Gamma-ray spectra in the energy range $0-2000 \mathrm{keV}$ recorded during $27,330 \mathrm{~s}$ for the iron foil (red) and during $46,454 \mathrm{~s}$ for the active background (black). Background gamma rays are marked with asterisks. Prompt gamma-rays of iron are written in bold. Abbreviations SE and DE stand for single and double escape peak (color figure online)
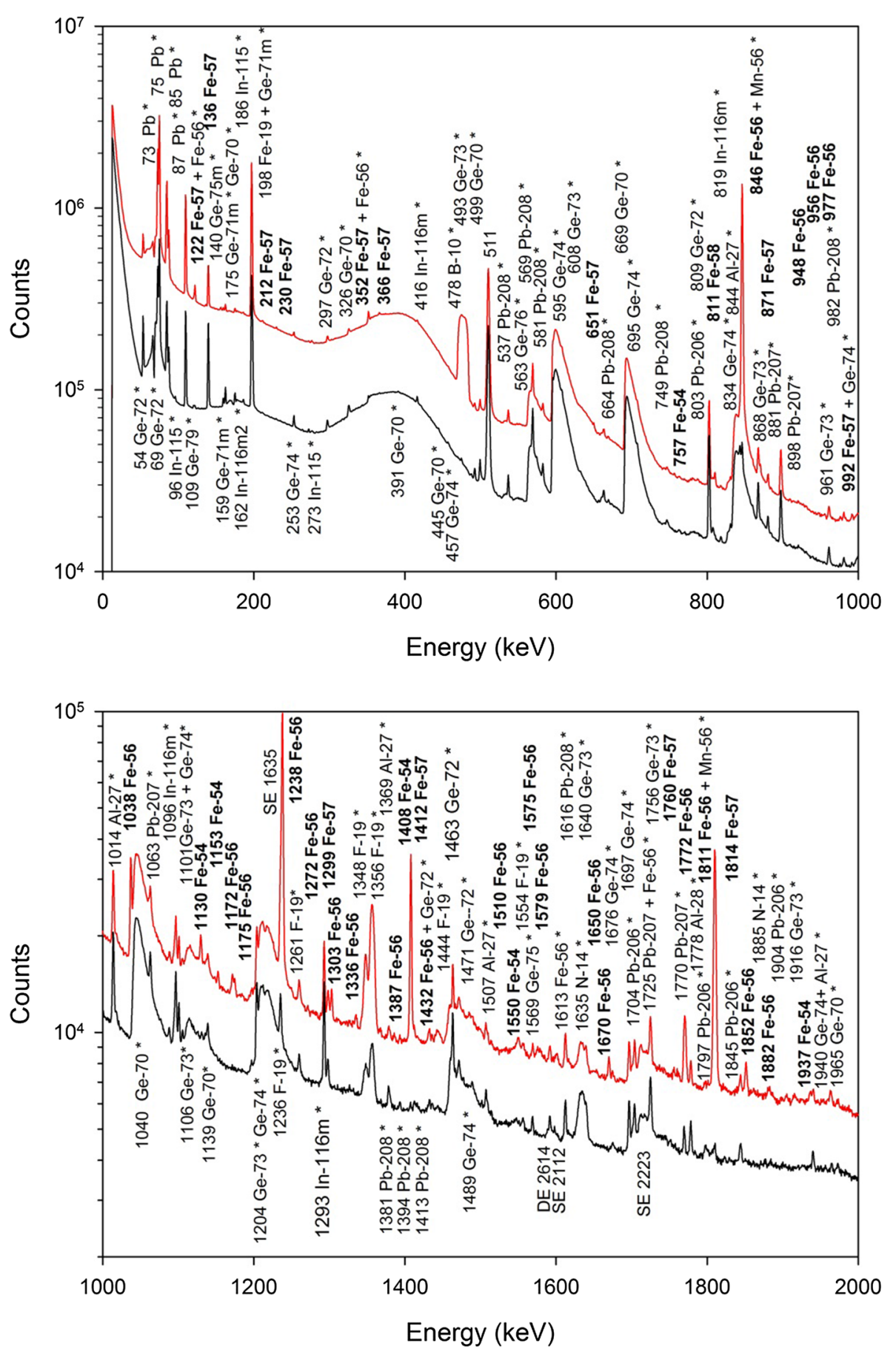
Fig. 5 Gamma-ray spectra in the energy range 2000$4000 \mathrm{keV}$ recorded during $27,330 \mathrm{~s}$ for the iron foil (red) and during $46,454 \mathrm{~s}$ for the active background (black). Background gamma rays are marked with asterisks. Prompt gamma-rays of iron are written in bold. Abbreviations SE and DE stand for single and double escape peak (color figure online)
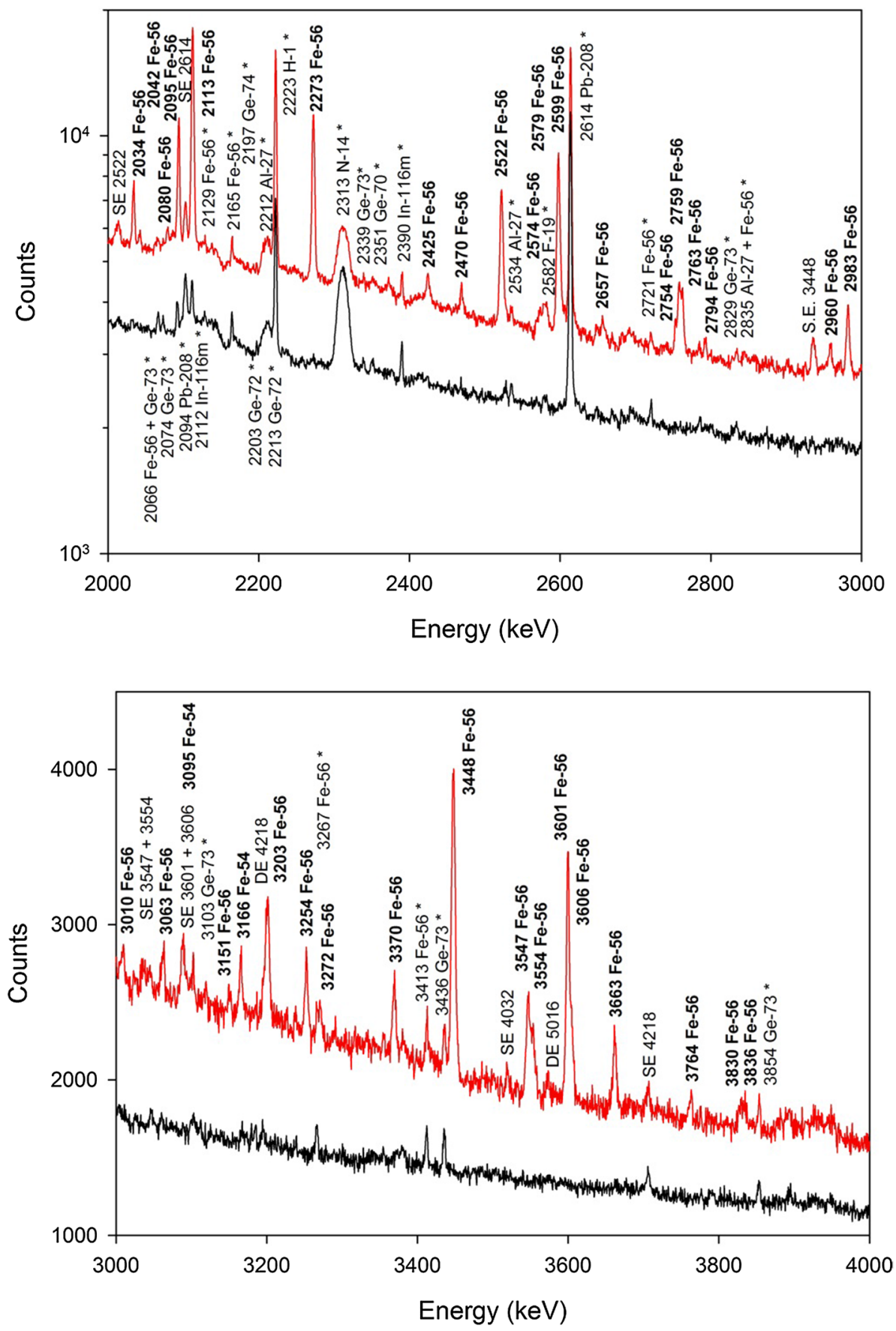

hydrogen gamma line is reduced by a factor of about 3 , both gamma rays being mainly produced in the front shielding.

Besides background lines, the spectrum of the iron contains the most intense prompt gamma rays induced by the inelastic scattering of fast neutrons on the iron isotopes ${ }^{54} \mathrm{Fe}$, ${ }^{56} \mathrm{Fe},{ }^{57} \mathrm{Fe}$ and ${ }^{58} \mathrm{Fe}$. Gamma lines of ${ }^{19} \mathrm{~F}$ also appear due to the sample packing made of Teflon. In comparison to the beam background, the count rates of lines attributed to the background are higher in the iron spectrum by a mean factor of $1.32 \pm 0.05$ due to neutrons scattered by the sample towards the detector. This factor was used to correct for the background interferences. The iron gamma rays were assigned to specific nuclear transitions of an iron isotope based on the database NuDat 2.8 [19]. Contributions from $(n, p)$ and $(n, \alpha)$ reactions were neglected due to their low cross sections compared to the $\left(n, n^{\prime}\right)$ reaction. A total of 81 prompt gamma lines of iron were identified, 59 associated to ${ }^{56} \mathrm{Fe}, 12$ to ${ }^{57} \mathrm{Fe}, 9$ to ${ }^{54} \mathrm{Fe}$ and 1 to ${ }^{58} \mathrm{Fe}$ (see Tables 2, 3, 4). Compared to the work of Demidov et al. [10], additional gamma lines were also detected $\left(23\right.$ for ${ }^{56} \mathrm{Fe}, 7$ for ${ }^{57} \mathrm{Fe}$ and 3 
Fig. 6 Gamma-ray spectra in the energy range 4000$8000 \mathrm{keV}$ recorded during $27,330 \mathrm{~s}$ for the iron foil (red) and during 46,454 $\mathrm{s}$ for the active background (black). Background gamma rays are marked with asterisks. Prompt gamma-rays of iron are written in bold. Abbreviations SE and DE stand for single and double escape peak (color figure online)
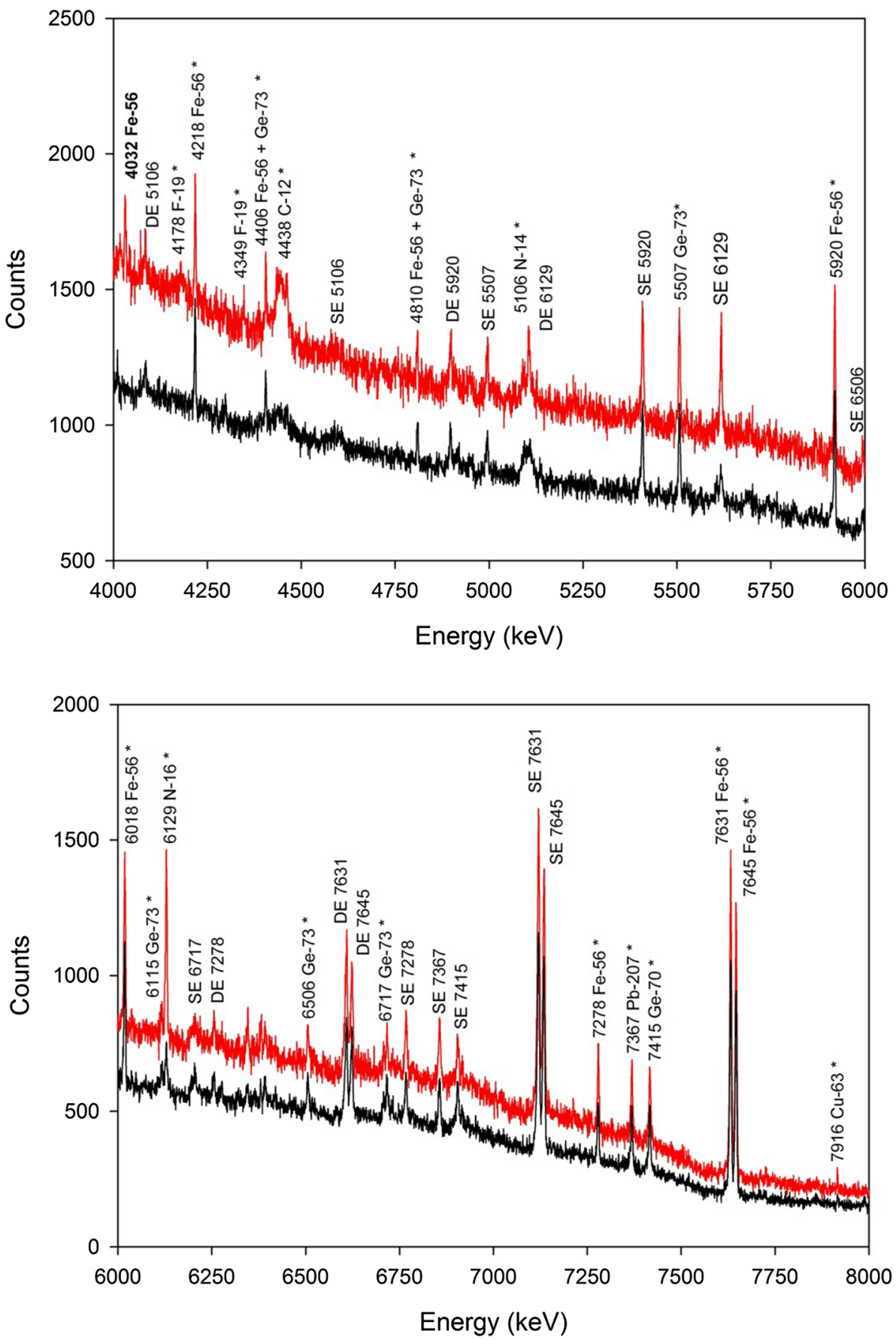

for $\left.{ }^{54} \mathrm{Fe}\right)$ due to the better resolution of our detector $(2.1 \mathrm{keV}$ vs. $3.8 \mathrm{keV}$ for the detector used in [10]). On the other hand, 13 gamma lines listed at energies 1213.0, 1359.9, 1454.5, 1528.6, 1612.2, 1725.6, 1760.8, 2211.7, 2027.0, 2062.4, $2192.9,3634.9$ and $4541.7 \mathrm{keV}$ in the Demidov Atlas were not observed. The line at $1359.9 \mathrm{keV}$ could not be uniquely identified due the Doppler broadening of the $1356.5 \mathrm{keV}$ line of ${ }^{19} \mathrm{~F}$ induced by interaction of fission neutrons with Teflon. It was not possible to observe the lines at 1612.2 and $1725.6 \mathrm{keV}$, respectively, due to interferences of the
$1612.8 \mathrm{keV}$ line of ${ }^{56} \mathrm{Fe}$ produced by thermal neutron capture of the iron frame and of the $1726.5 \mathrm{keV}$ line of ${ }^{207} \mathrm{~Pb}$ induced by inelastic scattering of fast neutrons with lead, respectively. Also, the line at $2211.7 \mathrm{keV}$ was not identified due to interference of the line at $2211.8 \mathrm{keV}$ of ${ }^{27} \mathrm{Al}$ issued from the inelastic scattering of fast neutrons with the aluminum cap of the detector. The remaining gamma rays which are not mentioned in the database NuDat 2.8 are probably assigned spuriously to iron in the Demidov Atlas, their intensities being measured with uncertainties as large as $50 \%$ in some 
Table 2 Prompt gamma rays of ${ }^{56} \mathrm{Fe}$

\begin{tabular}{|c|c|c|c|c|c|c|}
\hline \multicolumn{4}{|l|}{ This work } & \multicolumn{2}{|c|}{ From Demidov Atlas [10] } & \multirow{2}{*}{$\begin{array}{l}I_{\mathrm{R}}(\text { this } \\
\text { work }) / I_{\mathrm{R}} \\
\text { (Demidov) }\end{array}$} \\
\hline$E \gamma(\mathrm{keV})$ & $\begin{array}{l}P_{E \gamma}\left(90^{\circ}\right) / \varepsilon_{E \gamma} \\
\left(\times 10^{-8}\right) \text { (count) }\end{array}$ & $I_{\mathrm{R}}($ relative $)(\%)$ & $\left\langle\sigma_{E \gamma}\left(90^{\circ}\right)\right\rangle(\mathrm{mb})$ & $E \gamma(\mathrm{keV})$ & $I_{\mathrm{R}}($ relative $)(\%)$ & \\
\hline $846.86 \pm 0.04$ & $284 \pm 17$ & 100 & $586 \pm 41$ & 846.78 & 100 & 1 \\
\hline $948.3 \pm 0.3$ & $0.21 \pm 0.05$ & $0.07 \pm 0.02$ & $0.43 \pm 0.10$ & - & - & - \\
\hline $956.1 \pm 0.2$ & $0.33 \pm 0.06$ & $0.12 \pm 0.02$ & $0.67 \pm 0.13$ & - & - & - \\
\hline $976.8 \pm 0.2$ & $0.18 \pm 0.05$ & $0.06 \pm 0.02$ & $0.37 \pm 0.10$ & - & - & - \\
\hline $1037.81 \pm 0.05$ & $5.17 \pm 0.27$ & $1.82 \pm 0.14$ & $10.7 \pm 0.7$ & 1037.85 & $2.15 \pm 0.10$ & $0.85 \pm 0.08$ \\
\hline $1172.15 \pm 0.09$ & $0.74 \pm 0.05$ & $0.26 \pm 0.02$ & $1.5 \pm 0.1$ & $1173.2 \pm 0.8$ & $0.25 \pm 0.10$ & $1.04 \pm 0.42$ \\
\hline $1175.1 \pm 0.1$ & $0.58 \pm 0.05$ & $0.20 \pm 0.02$ & $1.2 \pm 0.1$ & $1175.0 \pm 0.8$ & $0.15 \pm 0.10$ & $1.33 \pm 0.90$ \\
\hline $1272.1 \pm 0.5$ & $0.19 \pm 0.05$ & $0.07 \pm 0.02$ & $0.40 \pm 0.10$ & $1271.9 \pm 0.1$ & $0.05 \pm 0.02$ & $1.40 \pm 0.70$ \\
\hline $1238.30 \pm 0.05$ & $28 \pm 2$ & $9.90 \pm 0.92$ & $58 \pm 5$ & $1238.3 \pm 0.2$ & $10.5 \pm 0.5$ & $0.94 \pm 0.10$ \\
\hline $1303.52 \pm 0.07$ & $0.93 \pm 0.07$ & $0.33 \pm 0.03$ & $1.9 \pm 0.2$ & $1303.2 \pm 0.3^{\mathrm{a}}$ & $0.64 \pm 0.10$ & $0.52 \pm 0.09$ \\
\hline $1335.7 \pm 0.2$ & $0.4 \pm 0.07$ & $0.14 \pm 0.02$ & $0.8 \pm 0.1$ & $1334.6 \pm 0.4$ & $0.18 \pm 0.03$ & $0.78 \pm 0.17$ \\
\hline $1386.6 \pm 0.4$ & $0.23 \pm 0.03$ & $0.08 \pm 0.01$ & $0.48 \pm 0.07$ & $1386.6 \pm 1.0$ & $0.06 \pm 0.03$ & $1.33 \pm 0.69$ \\
\hline $1432.5 \pm 0.2$ & $0.17 \pm 0.03$ & $0.06 \pm 0.01$ & $0.35 \pm 0.07$ & $1434.2 \pm 0.1$ & $0.05 \pm 0.02$ & $1.20 \pm 0.52$ \\
\hline $1575.8 \pm 0.2$ & $0.23 \pm 0.03$ & $0.08 \pm 0.01$ & $0.47 \pm 0.07$ & - & - & - \\
\hline $1579.5 \pm 0.2$ & $0.18 \pm 0.03$ & $0.06 \pm 0.01$ & $0.36 \pm 0.07$ & - & - & - \\
\hline $1650.4 \pm 0.5$ & $0.23 \pm 0.04$ & $0.08 \pm 0.01$ & $0.49 \pm 0.09$ & $1650.8 \pm 0.09$ & $0.09 \pm 0.03$ & $0.89 \pm 0.31$ \\
\hline $1670.7 \pm 0.1$ & $0.54 \pm 0.05$ & $0.19 \pm 0.02$ & $1.1 \pm 0.1$ & $1671.1 \pm 0.6^{\mathrm{b}}$ & $0.32 \pm 0.05$ & $0.59 \pm 0.11$ \\
\hline $1771.7 \pm 0.1$ & $1.48 \pm 0.13$ & $0.52 \pm 0.05$ & $3.1 \pm 0.3$ & $1771.33^{\mathrm{c}}$ & $0.91 \pm 0.08$ & $0.57 \pm 0.07$ \\
\hline $1810.77 \pm 0.05$ & $18 \pm 1$ & $6.32 \pm 0.59$ & $37 \pm 3$ & $1810.5 \pm 0.2$ & $6.9 \pm 0.5$ & $0.92 \pm 0.11$ \\
\hline $1852.00 \pm 0.07$ & $0.83 \pm 0.06$ & $0.29 \pm 0.03$ & $1.7 \pm 0.2$ & $1851.8 \pm 0.3$ & $0.39 \pm 0.06$ & $0.74 \pm 0.14$ \\
\hline $1882.3 \pm 0.4$ & $0.34 \pm 0.03$ & $0.12 \pm 0.01$ & $0.70 \pm 0.07$ & $1882.6 \pm 0.3$ & $0.33 \pm 0.05$ & $0.36 \pm 0.06$ \\
\hline $2015.1 \pm 0.2$ & $0.49 \pm 0.06$ & $0.17 \pm 0.02$ & $1.0 \pm 0.1$ & $2015 \pm 2$ & $0.15 \pm 0.08$ & $1.13 \pm 0.62$ \\
\hline $2034.66 \pm 0.06$ & $1.58 \pm 0.13$ & $0.56 \pm 0.06$ & $3.3 \pm 0.3$ & $2034.8 \pm 0.3$ & $0.46 \pm 0.07$ & $1.22 \pm 0.23$ \\
\hline $2042.9 \pm 0.2$ & $0.30 \pm 0.04$ & $0.11 \pm 0.02$ & $0.62 \pm 0.09$ & - & - & - \\
\hline $2079.9 \pm 0.2$ & $0.26 \pm 0.04$ & $0.09 \pm 0.01$ & $0.53 \pm 0.08$ & - & - & - \\
\hline $2094.70 \pm 0.06$ & $3.40 \pm 0.25$ & $1.20 \pm 0.11$ & $7.0 \pm 0.6$ & $2094.6 \pm 0.2$ & $1.08 \pm 0.07$ & $1.11 \pm 0.12$ \\
\hline $2113.11 \pm 0.07$ & $8.83 \pm 0.63$ & $3.10 \pm 0.29$ & $18 \pm 1$ & $2112.9 \pm 0.2$ & $3.2 \pm 0.2$ & $0.97 \pm 0.11$ \\
\hline $2273.41 \pm 0.06$ & $5.56 \pm 0.44$ & $1.95 \pm 0.19$ & $11 \pm 1$ & $2273.2 \pm 0.2$ & $2.03 \pm 0.12$ & $0.96 \pm 0.11$ \\
\hline $2372.6 \pm 0.5$ & $0.23 \pm 0.04$ & $0.08 \pm 0.02$ & $0.47 \pm 0.09$ & $2372.2 \pm 0.07$ & $0.09 \pm 0.03$ & $0.89 \pm 0.37$ \\
\hline $2425.5 \pm 0.1$ & $0.57 \pm 0.06$ & $0.20 \pm 0.02$ & $1.2 \pm 0.1$ & - & - & - \\
\hline $2470.2 \pm 0.2$ & $0.43 \pm 0.11$ & $0.15 \pm 0.04$ & $0.9 \pm 0.2$ & - & - & - \\
\hline $2522.42 \pm 0.09$ & $4.34 \pm 0.37$ & $1.53 \pm 0.16$ & $9.0 \pm 0.8$ & $2523.2 \pm 0.2$ & $1.28 \pm 0.10$ & $1.20 \pm 0.16$ \\
\hline $2574.4 \pm 0.2$ & $0.46 \pm 0.06$ & $0.16 \pm 0.02$ & $0.9 \pm 0.1$ & - & - & - \\
\hline $2579.2 \pm 0.2$ & $0.33 \pm 0.06$ & $0.12 \pm 0.02$ & $0.7 \pm 0.1$ & - & - & - \\
\hline $2598.9 \pm 0.2$ & $3.65 \pm 0.37$ & $1.28 \pm 0.15$ & $7.5 \pm 0.8$ & 2598.52 & $2.6 \pm 0.2$ & $0.49 \pm 0.07$ \\
\hline $2657.0 \pm 0.3$ & $0.45 \pm 0.06$ & $0.16 \pm 0.02$ & $0.9 \pm 0.1$ & $2658.3 \pm 0.8$ & $0.14 \pm 0.04$ & $1.14 \pm 0.36$ \\
\hline $2754.5 \pm 0.2$ & $0.56 \pm 0.06$ & $0.20 \pm 0.02$ & $1.2 \pm 0.1$ & - & - & - \\
\hline $2759.1 \pm 0.1$ & $1.4 \pm 0.1$ & $0.50 \pm 0.05$ & $2.9 \pm 0.3$ & $2760.0 \pm 0.3^{\mathrm{f}}$ & $1.24 \pm 0.10$ & $0.40 \pm 0.05$ \\
\hline $2763.4 \pm 0.1$ & $1.2 \pm 0.1$ & $0.44 \pm 0.05$ & $2.6 \pm 0.3$ & - & - & - \\
\hline $2793.9 \pm 0.3$ & $0.22 \pm 0.04$ & $0.08 \pm 0.02$ & $0.45 \pm 0.09$ & - & - & - \\
\hline $2959.7 \pm 0.2$ & $0.43 \pm 0.06$ & $0.15 \pm 0.02$ & $0.9 \pm 0.1$ & $2959.6 \pm 0.6$ & $0.20 \pm 0.04$ & $0.75 \pm 0.18$ \\
\hline $2983.2 \pm 0.1$ & $1.4 \pm 0.1$ & $0.50 \pm 0.05$ & $2.9 \pm 0.3$ & $2983.7 \pm 0.6$ & $0.46 \pm 0.7$ & $1.09 \pm 0.20$ \\
\hline $3010.0 \pm 0.4$ & $0.23 \pm 0.04$ & $0.08 \pm 0.02$ & $0.47 \pm 0.09$ & - & - & - \\
\hline $3063.6 \pm 0.3$ & $0.34 \pm 0.05$ & $0.12 \pm 0.02$ & $0.7 \pm 0.1$ & - & - & - \\
\hline $3151.6 \pm 0.4$ & $0.19 \pm 0.04$ & $0.07 \pm 0.01$ & $0.38 \pm 0.08$ & - & - & - \\
\hline $3202.8 \pm 0.2$ & $0.93 \pm 0.12$ & $0.33 \pm 0.05$ & $1.9 \pm 0.3$ & $3202.18^{d}$ & $0.78 \pm 0.13$ & $0.42 \pm 0.02$ \\
\hline $3253.8 \pm 0.2$ & $0.68 \pm 0.06$ & $0.24 \pm 0.03$ & $1.4 \pm 0.1$ & $3253.7 \pm 0.6$ & $0.36 \pm 0.7$ & $0.67 \pm 0.13$ \\
\hline
\end{tabular}


Table 2 (continued)

\begin{tabular}{|c|c|c|c|c|c|c|}
\hline \multicolumn{4}{|l|}{ This work } & \multicolumn{2}{|c|}{ From Demidov Atlas [10] } & \multirow{2}{*}{$\begin{array}{l}I_{\mathrm{R}} \text { (this } \\
\text { work) } / I_{\mathrm{R}} \\
\text { (Demidov) }\end{array}$} \\
\hline$E \gamma(\mathrm{keV})$ & $\begin{array}{l}P_{E \gamma}\left(90^{\circ}\right) / \varepsilon_{E \gamma} \\
\left(\times 10^{-8}\right) \text { (count) }\end{array}$ & $I_{\mathrm{R}}($ relative $)(\%)$ & $\left\langle\sigma_{E \gamma}\left(90^{\circ}\right)\right\rangle(\mathrm{mb})$ & $E \gamma(\mathrm{keV})$ & $I_{\mathrm{R}}($ relative $)(\%)$ & \\
\hline $3272.6 \pm 0.3$ & $0.28 \pm 0.04$ & $0.10 \pm 0.02$ & $0.58 \pm 0.09$ & $3272.6 \pm 1.0^{\mathrm{e}}$ & $0.17 \pm 0.04$ & $0.59 \pm 0.18$ \\
\hline $3370.2 \pm 0.2$ & $0.62 \pm 0.06$ & $0.22 \pm 0.03$ & $1.3 \pm 0.1$ & $3369.2 \pm 0.8$ & $0.24 \pm 0.05$ & $0.92 \pm 0.23$ \\
\hline $3447.7 \pm 0.3$ & $1.9 \pm 0.3$ & $0.68 \pm 0.10$ & $4.0 \pm 0.5$ & $3448.6 \pm 0.4$ & $1.13 \pm 0.20$ & $0.62 \pm 0.14$ \\
\hline $3547.5 \pm 0.2$ & $0.94 \pm 0.13$ & $0.33 \pm 0.05$ & $1.9 \pm 0.3$ & $3548.5 \pm 0.5^{\mathrm{g}}$ & $0.65 \pm 0.16$ & $0.51 \pm 0.15$ \\
\hline $3554.1 \pm 0.4$ & $0.56 \pm 0.06$ & $0.20 \pm 0.02$ & $1.2 \pm 0.1$ & - & - & - \\
\hline $3600.7 \pm 0.2$ & $2.5 \pm 0.3$ & $0.86 \pm 0.10$ & $5.1 \pm 0.6$ & $3601.9 \pm 0.3^{\mathrm{h}}$ & $1.5 \pm 0.3$ & $0.60 \pm 0.14$ \\
\hline $3606.0 \pm 0.2$ & $0.75 \pm 0.13$ & $0.27 \pm 0.05$ & $1.6 \pm 0.3$ & - & - & - \\
\hline $3662.9 \pm 0.3$ & $0.76 \pm 0.13$ & $0.27 \pm 0.05$ & $1.6 \pm 0.3$ & $3663.1 \pm 0.6$ & $0.43 \pm 0.14$ & $0.63 \pm 0.24$ \\
\hline $3763.7 \pm 0.4$ & $0.27 \pm 0.04$ & $0.10 \pm 0.02$ & $0.56 \pm 0.09$ & - & - & - \\
\hline $3828.1 \pm 0.5$ & $0.25 \pm 0.04$ & $0.09 \pm 0.02$ & $0.52 \pm 0.09$ & - & - & - \\
\hline $3833.8 \pm 0.5$ & $0.23 \pm 0.04$ & $0.08 \pm 0.02$ & $0.48 \pm 0.09$ & - & - & - \\
\hline $4032.4 \pm 0.3$ & $0.38 \pm 0.01$ & $0.13 \pm 0.01$ & $0.79 \pm 0.03$ & - & - & - \\
\hline
\end{tabular}

$E \gamma$ is the gamma-ray energy, $P_{E \gamma}\left(90^{\circ}\right) / \varepsilon_{E \gamma}$ the net count in the gamma ray peak divided by the full-energy-peak efficiency, $I_{\mathrm{R}}$ the relative intensity of the gamma ray and $\left\langle\sigma_{E \gamma}\left(90^{\circ}\right)\right\rangle$ the fast neutron spectrum averaged isotopic cross section for gamma ray production at angle of $90^{\circ}$ between neutron beam and detector determined with Eq. (2)

Possible interference from ${ }^{\mathrm{a}}$ the $1298 \mathrm{keV}$ line of ${ }^{57} \mathrm{Fe}$; ${ }^{\mathrm{b}}$ the $1676 \mathrm{keV}$ line of ${ }^{74} \mathrm{Ge}$; ${ }^{\mathrm{c}}$ the $1770 \mathrm{keV}$ line of ${ }^{207} \mathrm{~Pb}$; ${ }^{\mathrm{d}}$ the double escape peak of the $4218 \mathrm{keV}$ line, ${ }^{\mathrm{e}}$ affected by the $3267 \mathrm{keV}$ neutron capture line of ${ }^{56} \mathrm{Fe}$. Not resolved doublet: ${ }^{\mathrm{f}} 2759$ and $2764 \mathrm{keV}$; ${ }^{\mathrm{g}} 3547$ and $3554 \mathrm{keV}$; ${ }^{\mathrm{h}} 3601$ and $3606 \mathrm{keV}$

Table 3 Prompt gamma rays of ${ }^{57} \mathrm{Fe}$

\begin{tabular}{|c|c|c|c|c|c|c|}
\hline \multicolumn{4}{|l|}{ This work } & \multicolumn{2}{|c|}{ From Demidov Atlas [10] } & \multirow{2}{*}{$\begin{array}{l}I_{\mathrm{R}} \text { (this } \\
\text { work) } / I_{\mathrm{R}} \\
\text { (Demidov) }\end{array}$} \\
\hline$E \gamma(\mathrm{keV})$ & $\begin{array}{l}P_{E \gamma}\left(90^{\circ}\right) / \varepsilon_{E \gamma} \\
\left(\times 10^{-8}\right) \text { (count) }\end{array}$ & $I_{\mathrm{R}}($ relative $)(\%)$ & $\left\langle\sigma_{E \gamma}\left(90^{\circ}\right)\right\rangle(\mathrm{mb})$ & $E \gamma(\mathrm{keV})$ & $I_{\mathrm{R}}($ relative $)(\%)$ & \\
\hline $121.84 \pm 0.05$ & $3.63 \pm 0.24$ & $1.28 \pm 0.11$ & $324 \pm 24$ & $122.1 \pm 0.2$ & $2.2 \pm 0.2$ & $0.58 \pm 0.07$ \\
\hline $136.33 \pm 0.08$ & $0.36 \pm 0.08$ & $0.13 \pm 0.03$ & $32 \pm 7$ & - & - & - \\
\hline $211.7 \pm 0.1$ & $0.29 \pm 0.07$ & $0.10 \pm 0.02$ & $26 \pm 6$ & - & - & - \\
\hline $230.25 \pm 0.07$ & $0.26 \pm 0.05$ & $0.09 \pm 0.02$ & $23 \pm 4$ & - & - & - \\
\hline $352.13 \pm 0.04$ & $2.81 \pm 0.35$ & $0.99 \pm 0.14$ & $251 \pm 32$ & $352.5 \pm 0.0$ & $1.6 \pm 0.2$ & $0.62 \pm 0.12$ \\
\hline $366.48 \pm 0.08$ & $0.89 \pm 0.14$ & $0.31 \pm 0.05$ & $79 \pm 13$ & $367.1 \pm 0.2$ & $0.54 \pm 0.05$ & $0.57 \pm 0.18$ \\
\hline $650.65 \pm 0.08$ & $0.46 \pm 0.05$ & $0.16 \pm 0.02$ & $41 \pm 5$ & - & - & - \\
\hline $870.75 \pm 0.06$ & $0.96 \pm 0.08$ & $0.34 \pm 0.03$ & $85 \pm 8$ & - & - & - \\
\hline $992.5 \pm 0.1$ & $0.24 \pm 0.06$ & $0.08 \pm 0.02$ & $22 \pm 5$ & $992.8 \pm 0.4$ & $0.10 \pm 0.03$ & $0.80 \pm 0.31$ \\
\hline $1298.9 \pm 0.1$ & $0.20 \pm 0.11$ & $0.07 \pm 0.04$ & $18 \pm 10$ & $1298.9 \pm 0.4^{\mathrm{a}}$ & $0.12 \pm 0.04$ & $0.58 \pm 0.38$ \\
\hline $1412.4 \pm 0.2$ & $0.15 \pm 0.05$ & $0.05 \pm 0.02$ & $14 \pm 4$ & - & - & - \\
\hline $1814.0 \pm 0.2$ & $0.58 \pm 0.08$ & $0.20 \pm 0.03$ & $52 \pm 8$ & - & - & - \\
\hline
\end{tabular}

$E \gamma$ is the gamma-ray energy, $P_{E \gamma}\left(90^{\circ}\right) / \varepsilon_{E \gamma}$ the net count in the gamma ray peak divided by the full-energy-peak efficiency, $I_{\mathrm{R}}$ the relative intensity of the gamma ray and $\left\langle\sigma_{E \gamma}\left(90^{\circ}\right)\right\rangle$ the fast neutron spectrum averaged isotopic cross section for gamma ray production at angle of $90^{\circ}$ between neutron beam and detector determined with Eq. (2)

Possible interference from ${ }^{\mathrm{a}}$ the $1303 \mathrm{keV}$ line of ${ }^{56} \mathrm{Fe}$

cases. The intensities of the gamma rays were calculated relative to the $847-\mathrm{keV}$ line of ${ }^{56} \mathrm{Fe}(100 \%)$, and they are given with the values determined in [10] in Tables 2, 3 and 4. The ratios of the intensities are given in the last column of the tables. The average value of the ratios is $0.85 \pm 0.26$. For 25 gamma rays, the half of the data, the intensities agree well with each other taking into account their uncertainties. For the remaining gamma rays the intensities listed in Demidov Atlas are higher by factors ranging from 1.5 to 2.5 without following any trend according to the energy of the gamma rays. The cause for these high values may probably be due to the presence of the $5 \mathrm{~cm}$ thick iron plate in front 
Table 4 Prompt gamma rays of ${ }^{54} \mathrm{Fe}$ and ${ }^{58} \mathrm{Fe}$

\begin{tabular}{|c|c|c|c|c|c|c|}
\hline \multicolumn{4}{|l|}{ This work } & \multicolumn{2}{|c|}{ Demidov Atlas [10] } & \multirow{2}{*}{$\begin{array}{l}I_{\mathrm{R}}(\text { this } \\
\text { work }) / I_{\mathrm{R}} \\
\text { (Demidov) }\end{array}$} \\
\hline$E \gamma(\mathrm{keV})$ & $\begin{array}{l}P_{E \gamma}\left(90^{\circ}\right) / \varepsilon_{E \gamma} \\
\left(\times 10^{-8}\right) \text { (count) }\end{array}$ & $I_{\mathrm{R}}($ relative $)(\%)$ & $\left\langle\sigma_{E \gamma}\left(90^{\circ}\right)\right\rangle(\mathrm{mb})$ & $E \gamma(\mathrm{keV})$ & $I_{\mathrm{R}}($ relative $)(\%)$ & \\
\hline $757.6 \pm 0.2$ & $0.18 \pm 0.4$ & $0.06 \pm 0.01$ & $6 \pm 1$ & $757.3 \pm 0.4$ & $0.10 \pm 0.03$ & $0.60 \pm 0.21$ \\
\hline $1130.46 \pm 0.06$ & $1.06 \pm 0.08$ & $0.37 \pm 0.04$ & $34 \pm 3$ & $1130.0 \pm 0.3$ & $0.39 \pm 0.04$ & $0.95 \pm 0.14$ \\
\hline $1153.18 \pm 0.09$ & $0.42 \pm 0.04$ & $0.15 \pm 0.02$ & $13 \pm 1$ & $1152.8 \pm 0.4$ & $0.14 \pm 0.03$ & $1.07 \pm 0.27$ \\
\hline $1408.32 \pm 0.05$ & $9.92 \pm 0.58$ & $3.49 \pm 0.29$ & $321 \pm 22$ & $1408.2 \pm 0.2$ & $3.5 \pm 0.2$ & $1.00 \pm 0.10$ \\
\hline $1509.7 \pm 0.3$ & $0.23 \pm 0.04$ & $0.08 \pm 0.02$ & $0.49 \pm 0.09$ & $1509.7 \pm 0.10$ & $0.08 \pm 0.03$ & $1.00 \pm 0.53$ \\
\hline $1550.47 \pm 0.04$ & $0.45 \pm 0.08$ & $0.16 \pm 0.03$ & $14 \pm 3$ & $1551.2 \pm 0.4$ & $0.25 \pm 0.05$ & $0.64 \pm 0.18$ \\
\hline $1937.0 \pm 0.2$ & $0.29 \pm 0.03$ & $0.10 \pm 0.01$ & $9 \pm 1$ & - & - & - \\
\hline $3095.4 \pm 0.6$ & $0.20 \pm 0.04$ & $0.07 \pm 0.02$ & $6 \pm 1$ & - & - & - \\
\hline $3166.6 \pm 0.2$ & $0.37 \pm 0.06$ & $0.13 \pm 0.02$ & $12 \pm 2$ & - & - & - \\
\hline $810.67 \pm 0.07^{\mathrm{a}}$ & $1.17 \pm 0.19$ & $0.41 \pm 0.07$ & $786 \pm 130$ & $810.3 \pm 0.02$ & $0.43 \pm 0.03$ & $0.95 \pm 0.17$ \\
\hline
\end{tabular}

$E \gamma$ is the gamma-ray energy, $P_{E \gamma}\left(90^{\circ}\right) / \varepsilon_{E \gamma}$ the net count in the gamma ray peak divided by the full-energy-peak efficiency, $I_{\mathrm{R}}$ the relative intensity of the gamma ray and $\left\langle\sigma_{E \gamma}\left(90^{\circ}\right)\right\rangle$ the fast neutron spectrum averaged isotopic cross section for gamma ray production at angle of $90^{\circ}$ between neutron beam and detector determined with Eq. (2)

${ }^{\mathrm{a}}$ Gamma-ray of ${ }^{58} \mathrm{Fe}$

of the shielding of the Demidov's spectrometer as prompt gamma rays of iron are also visible in many spectra of the Demidov Atlas.

The net peak area of a prompt gamma ray of energy $E \gamma$ measured at the angle of $90^{\circ}$ between neutron beam and detector, $P_{E \gamma}\left(90^{\circ}\right)$, may be expressed by the following equation:

$P_{E \gamma}\left(90^{\circ}\right)=\frac{m}{M} \cdot N_{\mathrm{A}} \cdot h \cdot \varepsilon_{E \gamma} \cdot \sigma_{E \gamma}\left(90^{\circ}\right) \cdot \Phi \cdot t_{\mathrm{c}}$

where $m(\mathrm{~g})$ is the amount of element, $M\left(\mathrm{~g} \mathrm{~mol}^{-1}\right)$ the molar mass of the element, $N_{\mathrm{A}}$ the Avogadro number, $h$ the abundance of the isotope considered, $\Phi\left(\mathrm{cm}^{-2} \mathrm{~s}^{-1}\right)$ the integral fast neutron flux at sample position, $t_{\mathrm{c}}$ (s) the counting (live) time, $\varepsilon_{E \gamma}$ the full energy peak efficiency previously determined in [11] with the same gamma-ray collimation $(6 \mathrm{~cm}$ diameter opening). $\sigma_{E \gamma}\left(90^{\circ}\right)$ is the fast neutron spectrum averaged isotopic cross section for gamma ray production which may be given also by:

$\sigma_{E \gamma}\left(90^{\circ}\right)=\frac{\int_{E \min }^{E \max } \sigma_{E \gamma}\left(90^{\circ}, E\right) \cdot \varphi(E) \cdot \mathrm{d} E}{\int_{E \min }^{E \max } \varphi(E) \cdot \mathrm{d} E}$

where $\varphi(E)$ is the differential neutron flux density and $\sigma_{E \gamma}\left(90^{\circ}, E\right)$ the isotopic cross section for gamma ray production at the corresponding neutron energy $E$. The values of $\sigma_{E \gamma}\left(90^{\circ}\right)$ deduced by means of Eq. (2) are given in Tables 2, 3 and 4. Corrections for neutron absorption and multiple scattering and for gamma absorption were neglected since the iron foil is very thin.

To check the validity of the results, the values of $\sigma_{E \gamma}\left(90^{\circ}\right)$ were calculated for the strongest ${ }^{56} \mathrm{Fe}$ gamma-rays at 847,1238 and $1810 \mathrm{keV}$ using as reference their gamma-ray production cross sections measured for several discrete incident neutron energies at an angle of $125^{\circ}$ by Dickens et al. [20]. These values are listed together with the corresponding neutron energy bins in Table 5. According to [21] we can write:

$\sigma_{E \gamma}\left(90^{\circ}, E_{i}\right)=\sigma_{E \gamma}\left(125^{\circ}, E_{i}\right) \cdot\left[\frac{W_{E \gamma}\left(125^{\circ}, E_{i}\right)}{W_{E \gamma}\left(90^{\circ}, E_{i}\right)}\right]^{-1}$

where $\sigma_{E \gamma}\left(\theta, E_{i}\right)$ is the isotopic cross section for gammaray production determined at the angle $\theta$ between neutron beam and detector axis for an incident neutron energy $E_{i}$ and $W_{E \gamma}\left(\theta, E_{i}\right)$ the corresponding angular distribution factor. For gamma rays induced by inelastic scattering of neutrons the angular distribution factor is described quite accurately by the first even terms of the Legendre polynomial [23]:

$W_{E \gamma}\left(\theta, E_{i}\right)=1+a_{2}\left(E \gamma, E_{i}\right) \cdot P_{2}(\cos \theta)+a_{4}\left(E \gamma, E_{i}\right) \cdot P_{4}(\cos \theta)$

with

$P_{2}(\cos \theta)=\frac{1}{2} \cdot\left[3 \cdot(\cos \theta)^{2}-1\right]$

and

$P_{4}(\cos \theta)=\frac{1}{8} \cdot\left[35 \cdot(\cos \theta)^{4}-30 \cdot(\cos \theta)^{2}+3\right]$

In the case of the $847 \mathrm{keV}$ gamma ray the coefficients $a_{2}$ and $a_{4}$ were taken in [22] for neutron energies lower than $2 \mathrm{MeV}$ and read out from the figure 2 of Ref. [23] 


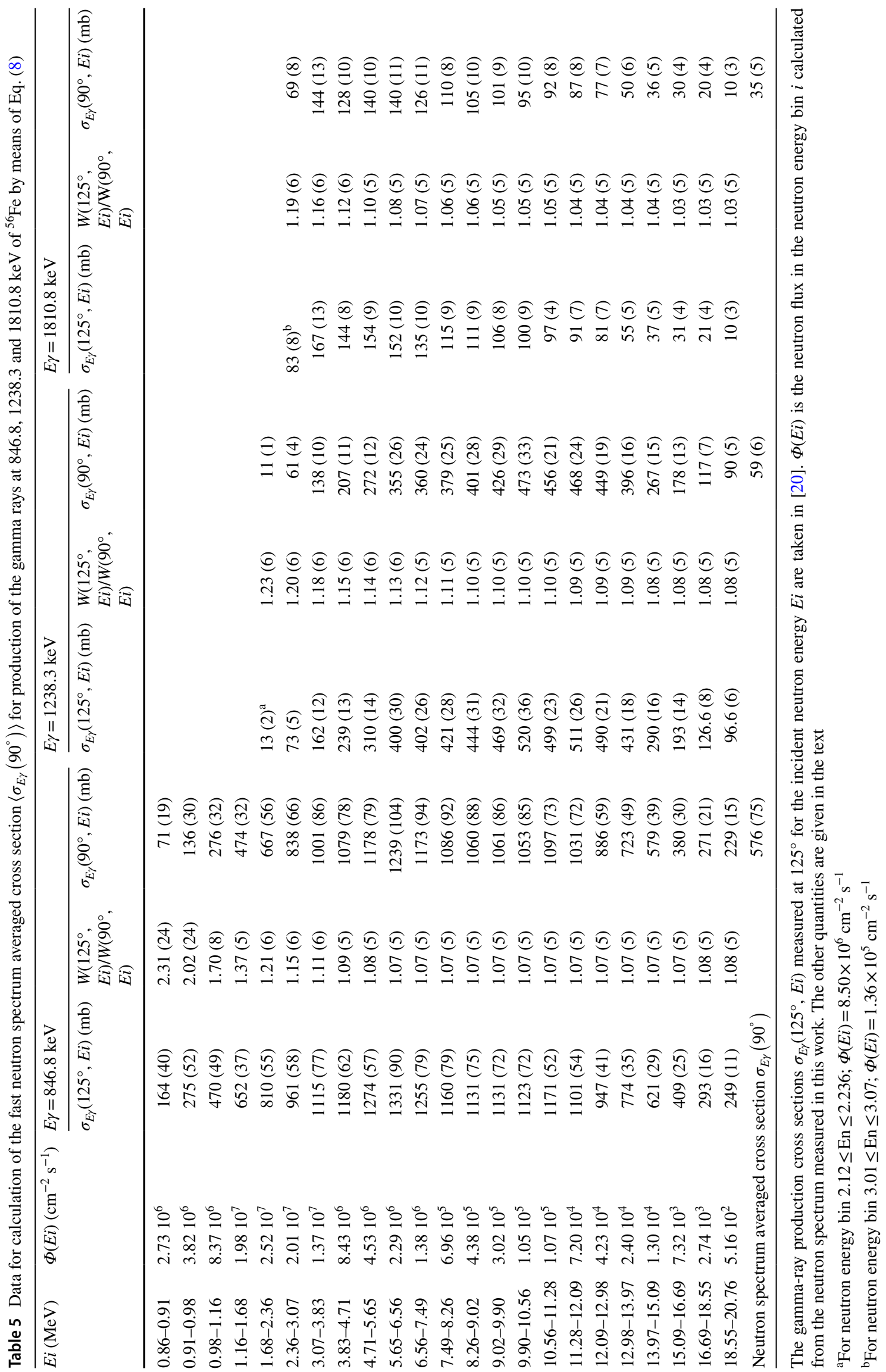


for higher neutron energies up to $14 \mathrm{MeV}$. For the gamma rays at 1238 and $1810 \mathrm{keV}$ the coefficients $\mathrm{a}_{2}$ were read out from the figure 2 of Ref. [23] and the coefficients $a_{4}$ being very small were assumed to be zero [23]. This assumption implies uncertainties less than 0.5 to $2 \%$ for the angular distribution factors depending on the ratio between $\mathrm{a}_{2}$ and $\mathrm{a}_{4}$. The neutron energy dependence of the ratio $W_{E \gamma}\left(125^{\circ}, E_{i}\right) / W_{E \gamma}\left(90^{\circ}, E_{i}\right)$ is shown for the aforementioned gamma-rays in Fig. 7. Analytical expressions were obtained by fitting the data with appropriate rational functions (solid lines in Fig. 7). As shown in Figs. 8 and 9 , respectively, the ratios $W_{E \gamma}\left(125^{\circ}, E_{i}\right) / W_{E \gamma}\left(90^{\circ}, E_{i}\right)$ calculated for the $847 \mathrm{keV}$ gamma ray and with the incident neutron energies between 0.95 and $4 \mathrm{MeV}$ and for the 1238 and $1810 \mathrm{keV}$ gamma rays at neutron energy of $4 \mathrm{MeV}$, respectively, agree well with the experimental values given in [24]. Thus, the method used in this work to evaluate the angular distribution factors of the gamma rays is consistent. The ratios $W_{E \gamma}\left(125^{\circ}, E_{i}\right) / W_{E \gamma}\left(90^{\circ}, E_{i}\right)$ as well as the values $<\sigma_{E \gamma}\left(90^{\circ}, E_{i}\right)>$ calculated by means of relation (4) using the cross sections measured at $125^{\circ}$ [20] are given in Table 5. It is interesting to note the convergence of the angular-distribution correction factors for the different types of radiation fields, the 847 and $1238 \mathrm{keV}$ gammas being stretched quadrupole $\mathrm{E} 2$ transitions while the $1811 \mathrm{keV}$ gamma is a mixed $\mathrm{M} 1+\mathrm{E} 2$ transition with a gamma-ray multipole mixing ratio of -0.18 [26].

The neutron spectrum averaged isotopic cross section for gamma-ray production was calculated with Eq. (8) which is an approximation for relation (3).
$\left\langle\sigma_{E \gamma}\left(90^{\circ}\right)\right\rangle=\frac{\sum_{i} \sigma_{E \gamma}\left(90^{\circ}, E_{i}\right) \cdot \Phi\left(E_{i}\right)}{\Phi}$

where $\Phi\left(E_{i}\right)$ is the neutron flux in the neutron energy bin i calculated from the neutron spectrum measured in this work (column 2 of Table 5) and $\Phi$ the fast neutron flux. The values of $\sigma_{E \gamma}\left(90^{\circ}\right)$ obtained with Eq. (8), are: $576 \pm 75 \mathrm{mb}$, $59 \pm 6 \mathrm{mb}$ and $35 \pm 5 \mathrm{mb}$ for the gamma-rays at 847,1238 and $1810, \mathrm{keV}$ respectively. These values agree well with the experimental values calculated with Eq. (2), $586 \pm 41$ $\mathrm{mb}, 58 \pm 5 \mathrm{mb}$ and $37 \pm 3 \mathrm{mb}$. Thus, we can assume that the neutron spectrum averaged isotopic cross sections for the production of the others iron prompt gamma rays detected in this work are reliable.

\section{Conclusions}

Prompt gamma-ray emission induced by inelastic scattering of fission neutrons on iron was measured with the FaNGaS instrument operated at MLZ. The measurements were performed at an angle of $90^{\circ}$ between the neutron beam and the detector with a fast neutron flux of $1.40 \times 10^{8} \mathrm{~cm}^{-2} \mathrm{~s}^{-1}$ at sample position. A total of 81 prompt gamma rays were detected and their relative intensities (using the $847 \mathrm{keV}$ gamma-ray of ${ }^{56} \mathrm{Fe}$ as reference) and fast neutron spectrum averaged production cross sections were determined. Compared to the work of Demidov et al. [10], 33 gamma lines were detected additionally. We also found out that 11 gamma lines were wrongly assigned
Fig. 7 Neutron energy dependence of the ratio of the angular distribution factors for the three strongest rays of ${ }^{56} \mathrm{Fe}$. The solid lines represent the fit of the data with following rational functions: $\left(a+b \times E_{i}\right) /$ $\left(1+c \times \mathrm{E}_{\mathrm{i}}+d \times E_{i}^{2}\right)$ for the $847 \mathrm{keV}$ gamma line with $a=0.5984, b=-1.4842$, $c=-1.4835$ and $d=0.0048$; $\left(a+b \times E_{i}\right) /\left(1+c \times E_{i}\right)$ for the $1238 \mathrm{keV}$ gamma line with $a=2.0779, b=2.778$ and $c=2.1619 ;\left(a+b \times E_{i}\right) /$ $\left(1+c \times E_{i}\right)$ for the $1810 \mathrm{keV}$ gamma line with $a=-1.1930$, $b=1.3856$ and $c=-1.1786$

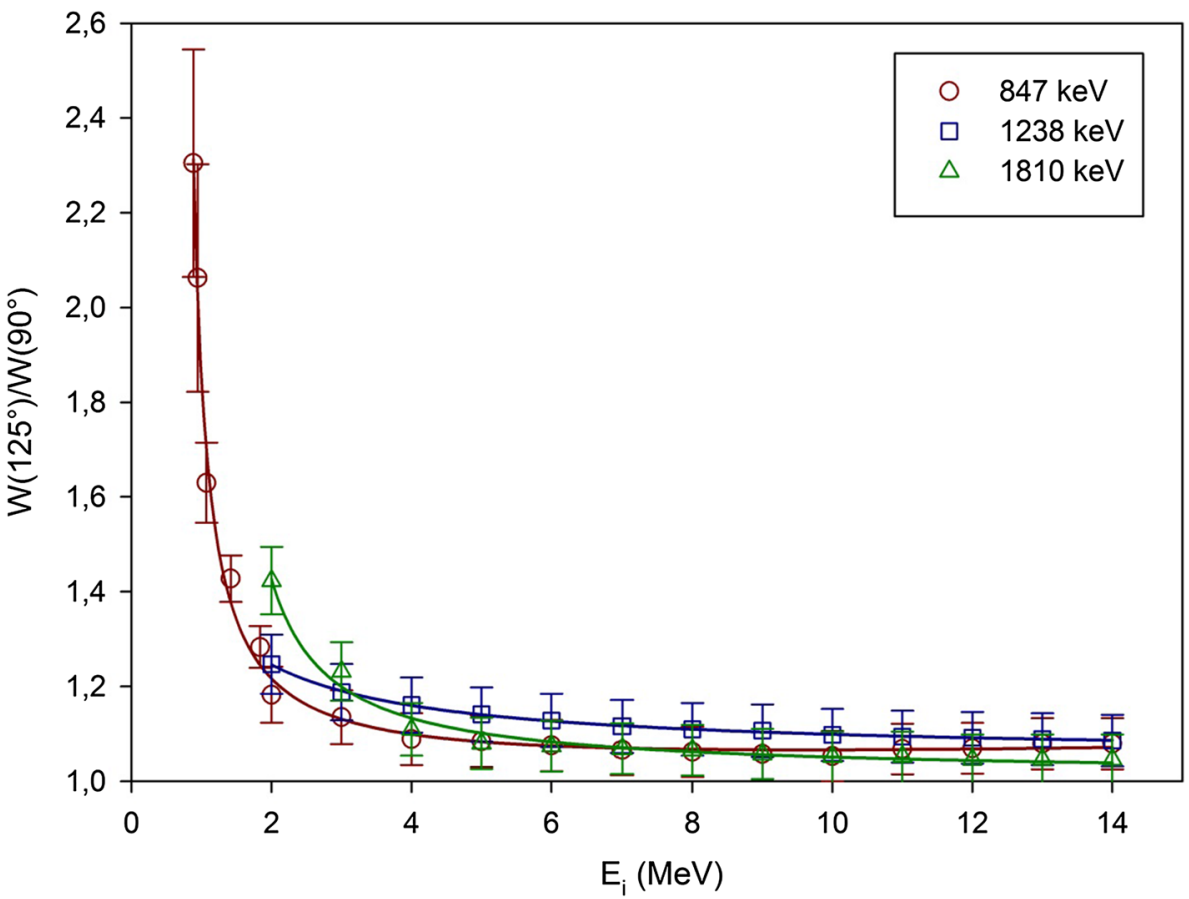



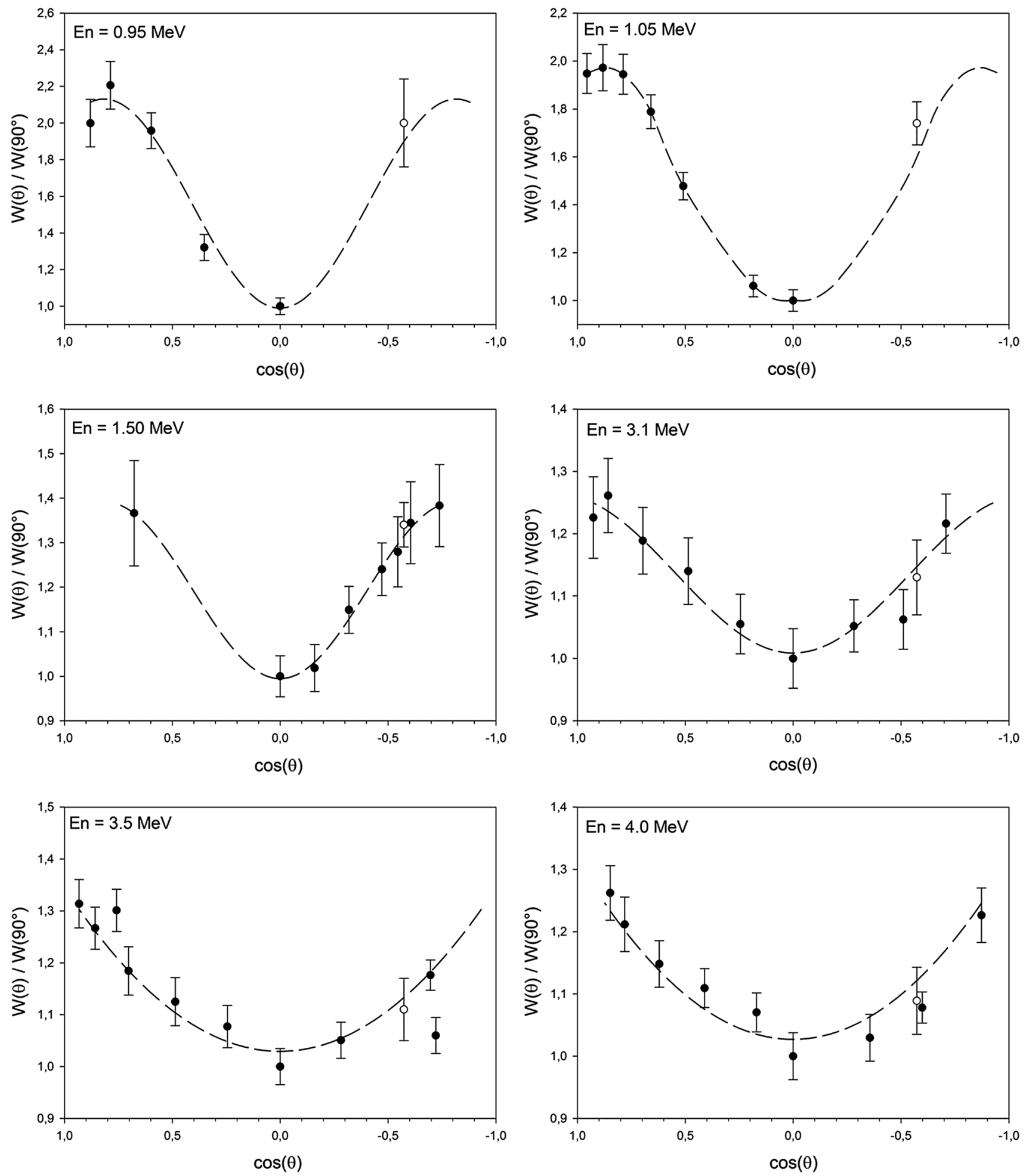

Fig. 8 Relative angular distributions for the $847 \mathrm{keV}$ gamma ray experimentally determined at several incident neutron energies (close symbols) [24] and value calculated in this work for $\theta=125^{\circ}$ (open

symbols). The dashed lines are fits of the data with a sinus function and serve as a guide to the eye 


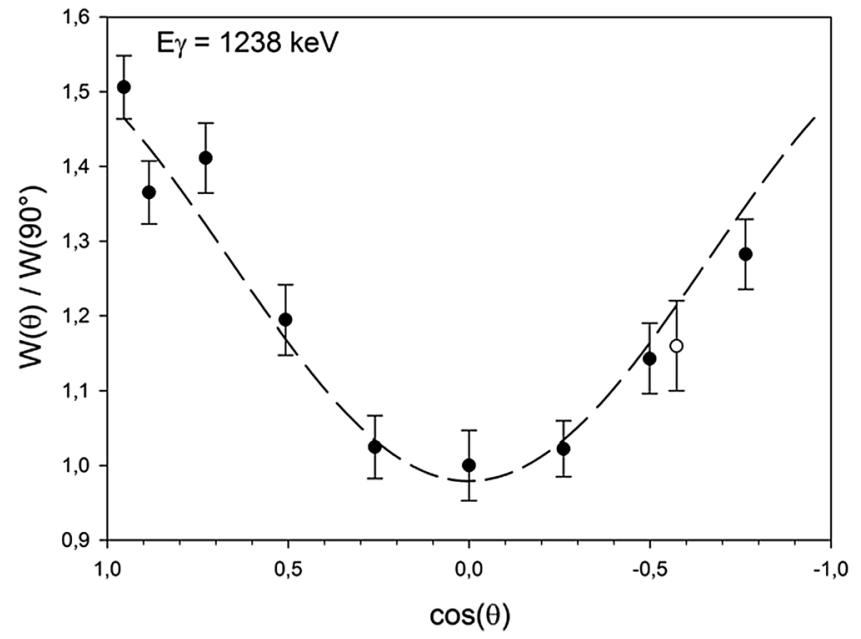

Fig. 9 Relative angular distributions for 1238 and $1811 \mathrm{keV}$ gamma rays experimentally determined at an incident neutron energy of $4 \mathrm{MeV}$ (close symbols) [24] and value calculated in this work for

to iron in the Demidov Atlas. For only the half of the gamma rays observed in both works, the intensities agree well with each other considering their uncertainties. For the remaining gamma rays the intensities listed in Demidov Atlas are largely higher probably due the presence of iron in the shielding of the Demidov's spectrometer. Additionally, the reliability of the gamma-ray production cross sections measured at $90^{\circ}$ was demonstrated from the gamma rays at 847,1238 and $1810 \mathrm{keV}$ by convoluting their discrete-energy gamma-ray production cross sections obtained at $125^{\circ}$ [20] with the fast neutron spectrum delivered at the sample position and taking into account angular correlation factors. Thus, the FaNGaS instrument proved to be a suitable tool to investigate fast neutron induced prompt gamma-ray emission to create a comprehensive data catalogue on $\left(n, n^{\prime} \gamma\right)$ reactions and to perform chemical analysis of large samples or small samples complementary to PGNAA with cold neutrons as well.

Acknowledgements Open Access funding provided by Projekt DEAL.

Open Access This article is licensed under a Creative Commons Attribution 4.0 International License, which permits use, sharing, adaptation, distribution and reproduction in any medium or format, as long as you give appropriate credit to the original author(s) and the source, provide a link to the Creative Commons licence, and indicate if changes were made. The images or other third party material in this article are included in the article's Creative Commons licence, unless indicated otherwise in a credit line to the material. If material is not included in the article's Creative Commons licence and your intended use is not permitted by statutory regulation or exceeds the permitted use, you will need to obtain permission directly from the copyright holder. To view a copy of this licence, visit http://creativecommons .org/licenses/by/4.0/.

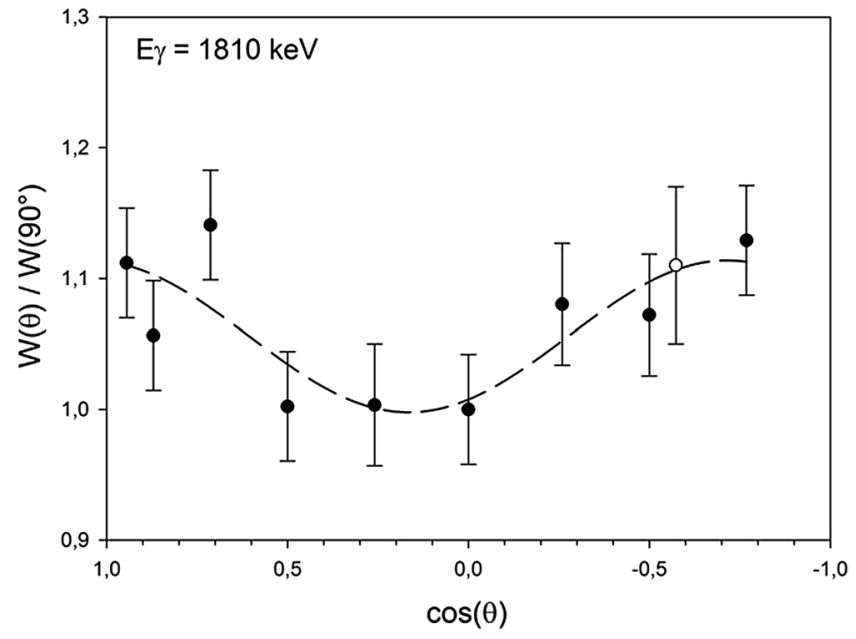

$\theta=125^{\circ}$ (open symbols). The dashed lines are fits of the data with a sinus function and serve as a guide to the eye

\section{References}

1. Molnár GL (2004) Handbook of prompt gamma activation analysis with neutron beams. Kluwer Academic Publishers ISBN 1-4020-1304-3

2. Sueki K, Kobayashi K, Sato W, Nakahara H, Tomizawa T (1996) Nondestructive determination of major elements in a large sample by prompt gamma ray neutron activation analysis. Anal Chem 68:2203-2209

3. Degenaar LH, Blaauw M, Bode P, de Goeij JJM (2004) Validation of MCNP for large sample thermal-beam prompt-gamma neutron activation analysis. J Radioanal Nucl Chem 2:311-315

4. Blaauw M, Degenaar LH, de Goeij JJM (2007) Development of a non-invasive method for the determination of the macroscopic neutron cross sections of a sample matrix in large-sample promptgamma neutron activation analysis. J Radioanal Nucl Chem 3:765-770

5. Blaauw M, Belgya T (2005) Neutron self-shielding correction for prompt gamma neutron activation analysis of large samples. J Radioanal Nucl Chem 265:257-259

6. Schrader CD, Stinner RJ (1961) Remote analysis of surfaces by neutron-gamma-ray inelastic scattering techniques. J Geophys Res 66:1951-1956

7. Jiggins AH, Habbani FI (1976) Prompt gamma-ray analysis using 3.29 MeV neutron inelastic scattering. Int J Appl Radiat Isot 27:689-693

8. Yates SW, Filo AJ, Cheng CY, Coope DF (1978) Elemental analysis by gamma detection following inelastic neutron scattering. J Radional Nucl Chem 46:343-355

9. Sowerby BD (1979) Elemental analysis by neutron inelastic scatter gamma rays with a radioisotope neutron source. Nucl Instrum Methods 166:571-579

10. Demidov A, Govor L, Cherepantsev M, Ahmed S, Al-Najiar M, Al-Amili N, Al-Assafi N, Rammo N (1978) Atlas of gamma-ray spectra from the inelastic scattering of reactor fast neutrons. Atomizdat, Moscow

11. Randriamalala TH, Rossbach M, Mauerhofer E, Zs Révay, Söllrad S, Wagner FM (2016) FaNGaS: a new instrument for (n, n', $\gamma)$ reaction measurements at FRM II. Nucl Instrum Methods A806:370-377 
12. Rossbach M, Randriamalala T, Mauerhofer E, Zs Révay, Söllrad S (2016) Prompt and delayed inelastic scattering from fission neutron irradiation-first results of FaNGas. J Radioanal Nucl Chem 309:149-154

13. Wagner FM, Kneschaurek P, Kastenmüller A, Loeper-Kabasakal B, Kampfer S, Breitkreutz H, Waschowski W, Molls M, Petry W (2008) The Munich fission neutron therapy facility MEDAPP at the research reactor FRM II. Strahlenther Onkol 184:643-646

14. Mühlbauer MJ, Büchert T, Kellermeier M, Knapp M, Makowska M, Schulz M, Zimmik S, Ehrenberg H (2018) Neutron imaging with fission and thermal neutrons at NECTAR at MLZ. Physica B 551:359-363

15. Zs Révay, Belgya T, Molnár GL (2005) Application of Hypermet-PC in PGAA. J Radioanal Nucl Chem 265:261-265

16. International Atomic Energy Agency. Codes for radiation damage calculations and neutron spectral adjustment. http://wwwnds.iaea.org/irdf2002/codes/index.htmlx

17. Perey FG (1977) Least-squares dosimetry unfolding: the program STAY'SL. ORNL/TM-6062, Oak Ridge National Laboratory, Oak Ridge, Tennessee

18. OECD NEA Data Bank, JANIS Book of neutron-induced crosssections (2018). https://www.oecd-nea.org/janis/book/book-neutr on-2018-05.pdf

19. NuDat 2.8 National Nuclear Data Center, Brookhaven National Laboratory. https://www.nndc.bnl.gov/nudat2/

20. Dickens JK, Todd JH, Larson DC (1990) Cross section for production of 70 discrete-energy gamma rays created by neutron interactions with ${ }^{56} \mathrm{Fe}$ for En to $40 \mathrm{MeV}$ : tabulated data. Report ORNL/TM-11671
21. Dietz M, Bemmerer D, Beyer R, Gohl S, Junghans AR, Kögler R, Massarczyk R, Müller SE, Schmidt K, Schwengner R, Szücs T, Takacs MP, Wagner A, Wagner L (2017) Angular distribution measurement of gamma rays from in inelastic neutron scattering on ${ }^{56} \mathrm{Fe}$ at the nELBE time-of-flight facility. In: EPJ Web of conferences, vol 146, p 11040

22. Dietz M (2016) Determination of the $\gamma$-ray-angular distribution in the inelastic scattering of fast neutrons on ${ }^{56} \mathrm{Fe}$ at nELBE. Master Thesis, Technische Universität Dresden, Germany. https://www. hzdr.de/publications/PublDoc-11136.pdf

23. Savin MV, Livke AV, YuYa Nefedov, Shvestsov MS, Zvenigorodskii AG, Blokhin AI (2000) Evaluation of angular distributions and gamma-rays production cross section for iron. J Nucl Sci Technol 37(Supplement 1):748-752

24. Benjamin RW, Buchanan PS, Morgan IL (1966) Gamma rays produced in the $56 \mathrm{Fe}\left(\mathrm{n}, \mathrm{n}^{\prime} \gamma\right) 56 \mathrm{Fe}$ reaction. Nucl Phys 79:241-256

25. Erdtmann G (1976) Neutron activation tables. Verlag Chemie, Weinheim

26. Bradley DI, Stone NJ, Rikovska J, Novakova D, Ferencei J (1986) Level spins and transition multipolarities in ${ }^{56} \mathrm{Fe}$ studied by nuclear orientation of ${ }^{56} \mathrm{Co}$. J Phys G Nucl Phys 12:115-128

Publisher's Note Springer Nature remains neutral with regard to jurisdictional claims in published maps and institutional affiliations. 